\begin{tabular}{|c|c|c|}
\hline $\begin{array}{l}\text { PKS } \\
\text { PUBLIC } \\
\text { KNOLLEDGE } \\
\text { PROJECT }\end{array}$ & $\begin{array}{l}\text { REVISTA DE GEOGRAFIA } \\
\text { (RECIFE) } \\
\text { http://www.revistaufpe.br/revistageografia }\end{array}$ & $\begin{array}{l}\text { OJS } \\
\text { OPEN } \\
\text { JOUNAL } \\
\text { SYSTEMS }\end{array}$ \\
\hline
\end{tabular}

\title{
APLICAÇÃO DO PROTOCOLO DE AVALIAÇÃO RÁPIDA DE RIOS DURANTE PERÍODO DE ESTIAGEM EM TRECHOS DA BACIA HIDROGRÁFICA DO RIBEIRÃO DA AREIA, GOIÁS
}

\author{
Leonardo Batista Pedroso ${ }^{1}$, Marlene Teresinha de Muno Colesanti ${ }^{2}$
}

\author{
${ }^{1}$ Instituto Federal Goiano. E-mail: leonardo.pedroso@ifgoiano.edu.br \\ ${ }^{2}$ Universidade Federal de Uberlândia.E-mail: mmuno@ufu.br
}

Artigo recebido em 31/03/2018 e aceito em 03/08/2018

\begin{abstract}
RESUMO
Este trabalho tem como objetivo aplicar o Protocolo de Avaliação Rápida de Rios - PAR em uma bacia hidrográfica presente ao Sul do Estado de Goiás, cujo curso d'água principal é o Ribeirão da Areia, tendo suas águas e de seus afluentes em uso constante por distintas atividades, das quais, ressaltam-se aquelas ligadas às atividades agropecuárias. Para tal, além da revisão bibliográfica que sustentasse o arcabouço teórico do trabalho, foi realizada adaptação de distintos PARs, elencando-se treze parâmetros, que visam avaliar as condições e o grau de intervenção dos cursos d'água e seus respectivos entornos, por meio do tipo de ocupação das margens, situação da cobertura vegetal, extensão da mata ciliar, transparência e características do fluxo das águas, entre outros. Aos respectivos parâmetros, foram atribuídas pontuações correspondentes à categoria de sua condição ambiental, onde 0 indica uma condição deficiente; 2 dispõe de uma condição intermediária; e 4 condição boa ou propícia do ambiente. A soma das pontuações permitiu a categorização do PAR nas condições ótima, boa, regular ou péssima. A média atribuída a bacia foi de 36 pontos, sendo que dos dez pontos, sete encontram-se na condição boa, dois na condição ótima e somente um regular.
\end{abstract}

Palavras-chave: PAR; Ribeirão da Areia; qualidade hídrica; bacia hidrográfica.

\section{APPLICATION OF THE PROTOCOL OF RAPID EVALUATION OF RIVERS DURING DROUGHT PERIOD IN PARTS OF HYDROGRAPHIC BASIN OF RIBEIRÃO DA AREIA, GOIÁS}

\begin{abstract}
This work has as objective apply the Protocol of Rapid Evaluation of Rivers - PRE in a river basin present at the South of the Goiás State, whose main watercourse is the Ribeirão da Areia, having its waters and its tributaries in constant use by distinct activities, of which, points up those linked to farming activities. For this, besides the bibliographic review that supported the theoretical framework of the work, was performed adaptation of different PRE's, Listing thirteen parameters, which aim to assess the conditions and degree of intervention of watercourses and their respective environments, by the type of occupation of the banks, situation of vegetation cover, extension of riparian vegetation, transparency and characteristics of the flow of water, among others. To the respective parameters, were assigned scores corresponding to the category of their environmental condition, where 0 indicates a poor condition; 2 has an intermediate condition; and 4 presents a good or propitious condition of the environment. The sum of the scores allowed categorization in the conditions great, good, regular, or very bad. The average attributed to the basin was 36 points, being that of the ten points, seven are in good condition, two in the great condition and only one in regular.
\end{abstract}

Keywords: PRE; Ribeirão da Areia; water quality; hydrographic basin. 


\section{INTRODUÇÃO}

A água, entendida como elemento essencial à vida humana, animal e vegetal, ao sofrer influência direta das atividades humanas, apresenta mudanças quanto às suas propriedades físico-químicas, alterando os padrões de potabilidade básicos ao consumo e em meio natural gerando desequilíbrios ambientais. A utilização cada vez mais intensa tem provocado, além dos problemas de qualidade, a escassez do recurso, afetando a sociedade e a qualidade ambiental como um todo (VON SPERLING, 1996; PHILIPPI JR., 2005; COLLISCHONN, TASSI, 2010).

Desta forma, a pressão sobre os recursos hídricos nas últimas décadas se traduz por uma série de impactos relacionados a qualidade e a disponibilidade das águas no Brasil. Nas áreas mais interioranas do país, prevalece o maior consumo da água sobre atividades-fim relacionadas à produção agropecuária. Em algumas propriedades rurais, ainda é possível constatar a ausência da leitura da legislação ambiental vigente.

A legislação vigente é pautada pela Política Nacional de Recursos Hídricos (PNRH), estabelecida pela Lei $n^{\circ}$ 9.433/97 - A Lei das Águas de 1997 -, cujo documento final foi aprovado pelo Conselho Nacional de Recursos Hídricos em 2006, é a principal política e instrumento norteador da gestão das águas no Brasil. O plano é coordenado pelo Ministério do Meio Ambiente e visa:

Estabelecer um pacto nacional para a definição de diretrizes e políticas públicas voltadas para a melhoria da oferta de água, em qualidade e quantidade, gerenciando as demandas e considerando a água um elemento estruturante para a implementação das políticas setoriais, sob a ótica do desenvolvimento sustentável e da inclusão social. (BRASIL, 2003, p.10).

O principal instrumento legal ligado à PNRH que visa o controle da qualidade hídrica, neste caso, é a Resolução CONAMA n. ${ }^{\circ}$ 357, de 17 de março de 2015, que "dispõe sobre a classificação dos corpos de água e diretrizes ambientais para o seu enquadramento, bem como estabelece as condições e padrões de lançamento de efluentes, e dá outras providências". Por meio do estabelecimento de limites e/ou volumes máximos permitidos para cada parâmetro de qualidade hídrica, este instrumento estabelece classes de uso das águas.

Em seu Capítulo II - Da Classificação dos Corpos de Água, Seção I - Das Águas Doces, Art. $4^{\circ}$, que visa classificação das mesmas, tem-se a divisão em: Classe Especial, Classes 1, 2, 3 e 4. Normalmente, para fins de abastecimento e utilização em projetos de agricultura irrigada, adota-se o padrão de Classe 2, que permite abastecimento para consumo humano após tratamento convencional e também à irrigação de hortaliças, plantas frutíferas e 
de parques, jardins, campos de esporte e lazer, com os quais o público possa vir a ter contato direto, o que é mais comum na região supracitada.

Muito além dos instrumentos políticos de controle ambiental dos recursos hídricos, há, em âmbito acadêmico, métodos que visam a avaliação da qualidade das águas e de seu respectivo entorno. Além dos métodos de análise dos parâmetros físico-químicos e microbiológicos/bacteriológicos das amostras de corpos hídricos, alguns pesquisadores, pautados em relatórios de agências governamentais de controle da qualidade ambiental, desenvolveram os Protocolos de Avaliação Rápida de Rios (PARs).

Diversas agências governamentais de controle da qualidade ambiental têm utilizado diferentes métodos de avaliação ecológica de rios, suas cabeceiras e todo seu entorno, levando-se em consideração a bacia hidrográfica como unidade de planejamento. Buscam uma abordagem com a disposição de um sistema de referência que visa avaliar as condições de preservação da biodiversidade e da qualidade ambiental. Desta forma, ao avaliar distintos ambientes, comparam diferentes graus de intervenção antrópica e, por meio de relatórios, apontam em níveis diferentes de urgência a necessidade de adequação ambiental, restauração e conservação de bacias hidrográficas (CALLISTO, et al., 2002; RODRIGUES, 2008).

Uma dessas técnicas de avaliação e monitoramento são os protocolos de avaliação rápida de rios (PAR), que se constituem em sistemas de avaliação qualitativa rápida de recursos hídricos superficiais que, em âmbito geral, indicam com certo grau de precisão, a qualidade ambiental dos cursos d'água e seus respectivos entornos/ambientes (BIZZO, MENEZES, ANDRADE, 2014). Diferentemente de análises geoestatísticas, como aquelas realizadas por meio de uso de técnicas específicas em sistemas de informações geográficas, esta modalidade de avaliação caracteriza-se por análises in locu, isto é, no exato local de ocorrência dos fenômenos analisados.

Se realizados em conjunto com análises geoestatísticas e espaciais, estas ferramentas apresentam grande valor científico para pesquisas de cunho ambiental. A diferença básica entre ambas se estabelece pela necessidade da realização de trabalhos de campo por parte das avaliações rápidas, necessitando assim, de planejamento prévio, evitando contratempos provenientes de intempéries climáticas (como eventos pluviométricos concentrados em períodos chuvosos), identificando vias de acesso e até mesmo período do dia relacionado à coleta de informações.

A variabilidade de parâmetros inclui, além de variáveis ecológico-ambientais, aspectos e formas de uso e ocupação, demonstrando graus de intervenção antrópica. Assim, o 
observador, na perspectiva espacial, é guiado por uma sequência de variáveis, que vão, desde a presença e densidade de matas ripárias, até a proximidade de instalações e empreendimentos industriais próximos.

Assim sendo, nos locais avaliados, é possível inferir quais são os aspectos que possuem maior peso quanto à interferência da qualidade dos ambientes entornos aos corpos hídricos, constituindo-se enquanto uma importante ferramenta para a gestão ambiental local.

Porém, por se tratar de uma análise visual de ecossistemas fluviais, os pesquisadores devem estar preparados para a avaliação e aplicação dos protocolos, necessitando também conhecer anteriormente a área onde se pretende aplicar a avaliação (CALLISTO et al., 2002).

A aplicação de tais protocolos faz-se necessária, na medida em que ocorre a intensificação de atividades de uso e ocupação do solo em áreas de bacias hidrográficas, gerando a degradação de cursos d'água e seus respectivos entornos.

Desta forma, este trabalho tem como objetivo aplicar o PAR em uma importante bacia hidrográfica presente ao Sul do Estado de Goiás, cujo curso d'água principal é o Ribeirão da Areia, tendo suas águas e de seus afluentes em uso constante por distintas atividades, das quais, ressaltam-se aquelas ligadas às atividades agropecuárias.

Para o respectivo recorte espacial, a maior parte dos estudos realizados refere-se a análises de parâmetros físico-químicos e microbiológicos da água em distintos pontos. Os estudos carecem de análises ambientais qualitativas pautadas na análise da paisagem e do estado de conservação do ambiente. Deste modo, a adaptação desta metodologia ao respectivo recorte, bem como o resultado gerado na categorização ambiental, permitirá aos órgãos públicos locais, gestores das águas e usuários, a compreensão do quadro de conservação e o desenvolvimento de ações para a manutenção da qualidade do ambiente local.

\section{PROCEDIMENTOS METODOLÓGICOS}

Para sustentar o arcabouço teórico da pesquisa, bem como fundamentar adaptações de protocolos aplicados por outros pesquisadores em outros recortes espaciais, foi essencial a realização de uma revisão da literatura científica sobre a temática de recursos hídricos, qualidade das águas e protocolos de avaliação rápida de rios. Essa revisão foi realizada mediante análise de artigos de periódicos científicos especializados, bem como em livros e materiais dispostos em acervo digital.

Em relação aos PARs, ressalta-se que muitos destes aplicados em pesquisas recentes seguem metodologia (e ou respectiva adaptação) da Agência de Proteção Ambiental de Ohio 
(EUA) (EPA,1987) e Hannaford et al. (1997), como é o caso de Callisto et al. (2002). Rodrigues (2008), por sua vez, baseou-se na avaliação global do habitat cujo modelo é de Barbour et al. (1999).

O protocolo elaborado para esta pesquisa constitui-se enquanto uma adaptação dos protocolos de Hannaford et al. (1997), EPA (1987) e Rodrigues (2008). A adaptação foi necessária no que diz respeito ao levantamento de parâmetros de maior importância para a análise ambiental dos cursos d'água desta região, predominantemente inseridos em região de Cerrado. Assim sendo, muitos parâmetros presentes nas metodologias citadas, bem como suas respectivas pontuações atribuídas pelos autores não se encontram nesta por não se enquadrarem no âmbito do recorte espacial desta pesquisa.

Foram elencados os seguintes parâmetros de análise, conforme Quadro 1.

Quadro 1 - Parâmetros do protocolo de avaliação rápida de rios.

\section{Parâmetros}

1. Tipo de ocupação das margens do corpo d'água (principal atividade)

2. Erosão próxima e/ou nas margens do rio e assoreamento em seu leito

3. Alterações antrópicas

4. Cobertura vegetal no leito

5. Presença de mata ciliar

6. Extensão de mata ciliar

7. Odor da água

8. Oleosidade da água

9. Transparência da água

10. Odor do sedimento

11. Tipo de fundo

12. Alterações no canal do rio

13. Características do fluxo das águas

Fonte: Adaptado de Hannaford et al. (1997), EPA (1987) e Rodrigues (2008).

Aos respectivos parâmetros, foram atribuídas pontuações correspondentes à categoria de sua condição ambiental, sendo essa condição associada à três prováveis pontuações: 0,2 ou 4 pontos por parâmetro; onde 0 indica uma condição ruim, deficiente; 2 dispõe de uma condição intermediária; e 4 apresenta uma condição boa ou propícia do ambiente analisado para o respectivo atributo.

As análises são feitas in loco, com análises qualitativas do PAR, e aferições da temperatura ambiente e da água, com utilização de termômetros, trena para medição da 
largura do canal e aparelho GPS para registro de coordenadas geográficas do local, conforme Figura 1.

Figura 1 - Coleta e registro de coordenadas geográficas; procedimentos analíticos de registro do PAR.
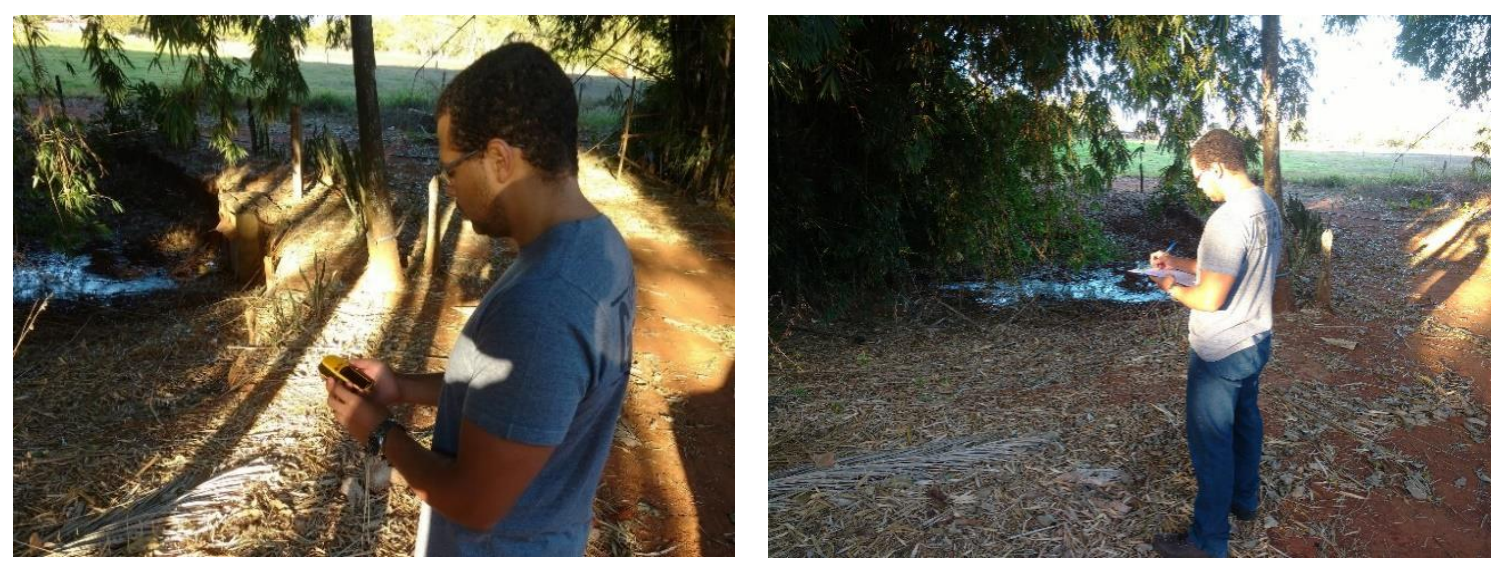

Autor: Yan Lemke de Castro, 2016.

A distribuição da pontuação para cada um dos parâmetros supracitados se dá conforme modelo de análise apresentado no Quadro 2.

Após avaliação individual de cada item do protocolo, foi realizada a soma das pontuações atribuídas e, então atribuída a respectiva categorização para o trecho de análise, conforme definição do padrão disposto na Tabela 1.

Tabela 1 - Categorização das condições ambientais do PAR.

\begin{tabular}{cc}
\hline Categorias das condições & Pontuações \\
\hline Ótima & 41 a 52 \\
Boa & 27 a 40 \\
Regular & 13 a 26 \\
Péssima & 0 a 12 \\
\hline
\end{tabular}

Fonte: Os autores.

Um curso d'água pode se enquadrar em quatro categorias possíveis, sendo que aqueles que se alocam nas condições "Boa" e "Ótima", isto é, entre 27 e 52 pontos, dispõem de qualidade ambiental sustentável, atendendo aspectos relacionados à exigência do equilíbrio sistêmico natural local. As respectivas categorias também menor intervenção antrópica, se comparada aos cursos d'água enquadrados nas categorias "Regular" e "Péssima", as quais 
constata-se grande variação, ou alterações negativas do ponto de vista da observância de aspectos ecológicos.

Quadro 2 - Pontuação atribuída aos parâmetros de análise do Protocolo de Avaliação Rápida de Rios.

\begin{tabular}{|c|c|c|c|}
\hline & \multicolumn{3}{|c|}{ Pontuação } \\
\hline Parâmetros & 4 pontos & 2 pontos & 0 ponto \\
\hline $\begin{array}{lr}\text { 1.Tipo de } & \text { ocupação } \\
\text { das margens } & \text { do corpo } \\
\text { d'água } & \text { (principal } \\
\text { atividade) } & \\
\end{array}$ & Vegetação natural & $\begin{array}{c}\text { Campo de pastagem / agricultura / } \\
\text { reflorestamento }\end{array}$ & $\begin{array}{l}\text { Residencial/ Comercial/ } \\
\text { Industrial }\end{array}$ \\
\hline $\begin{array}{l}\text { 2. Erosão próxima } \\
\text { e/ou nas margens do } \\
\text { rio e assoreamento em } \\
\text { seu leito }\end{array}$ & $\begin{array}{l}\text { Margens estáveis; evidência de } \\
\text { erosão mínima ou ausente; } \\
\text { pequeno potencial para } \\
\text { problemas futuros }\end{array}$ & $\begin{array}{l}\text { Moderada; pequenas áreas de } \\
\text { erosão frequentes }\end{array}$ & $\begin{array}{c}\text { Acentuada e Instável; muitas } \\
\text { áreas com erosão; frequentes } \\
\text { áreas descobertas nas curvas do } \\
\text { rio }\end{array}$ \\
\hline $\begin{array}{l}3 . \quad \text { Alterações } \\
\text { antrópicas }\end{array}$ & Ausente & $\begin{array}{c}\text { Alterações de origem doméstica } \\
\text { (esgoto, lixo) }\end{array}$ & $\begin{array}{c}\text { Alterações de origem industrial/ } \\
\text { urbana (fábricas, siderurgias, } \\
\text { canalização, retilinização do } \\
\text { curso do rio) }\end{array}$ \\
\hline $\begin{array}{l}\text { 4. Cobertura vegetal } \\
\text { no leito }\end{array}$ & Total & Parcial & Ausente \\
\hline $\begin{array}{l}\text { 5. Presença de Mata } \\
\text { Ciliar }\end{array}$ & $\begin{array}{l}\text { Acima de } 80 \% \text { com vegetação } \\
\text { ripária nativa, incluindo } \\
\text { árvores, arbustos ou } \\
\text { macrófitas; mínima evidência } \\
\text { de desflorestamento }\end{array}$ & $\begin{array}{c}\text { Entre } 50 \text { e } 80 \% \text { com vegetação } \\
\text { ripária nativa; desflorestamento } \\
\text { parcial; trechos com solo exposto ou } \\
\text { vegetação eliminada }\end{array}$ & $\begin{array}{c}\text { Menos de } 50 \% \text { da mata ciliar } \\
\text { nativa; desflorestamento muito } \\
\text { acentuado }\end{array}$ \\
\hline $\begin{array}{l}\text { 6. Extensão de mata } \\
\text { ciliar }\end{array}$ & $\begin{array}{l}\text { Largura da vegetação ripária } \\
\text { maior que } 15 \mathrm{~m} \text {; sem influência } \\
\text { de atividades antrópicas } \\
\text { (agropecuária, estradas, etc.) }\end{array}$ & $\begin{array}{c}\text { Largura da vegetação ripária entre } \\
12 \text { e } 18 \text { m; mínima influência } \\
\text { antrópica }\end{array}$ & $\begin{array}{l}\text { Largura da vegetação ripária } \\
\text { menor que } 12 \mathrm{~m} \text {; vegetação } \\
\text { restrita ou ausente devido à } \\
\text { atividade antrópica }\end{array}$ \\
\hline 7. Odor da água & Nenhum & Esgoto (ovo podre) & Óleo/industrial \\
\hline 8. Oleosidade da água & Ausente & Moderada & Abundante \\
\hline $\begin{array}{l}\text { 9. Transparência da } \\
\text { água }\end{array}$ & Transparente & Turva/cor de chá-forte & Opaca ou colorida \\
\hline 10. Odor do sedimento & Nenhum & Esgoto (ovo podre) & Óleo/industrial \\
\hline 11. Tipo de fundo & Pedras/cascalho & Lama/areia & Cimento/canalizado \\
\hline $\begin{array}{l}\text { 12. Alterações no } \\
\text { canal do rio }\end{array}$ & $\begin{array}{l}\text { Canalização (retificação) ou } \\
\text { dragagem ausente ou mínima; } \\
\text { rio com padrão normal }\end{array}$ & $\begin{array}{c}\text { Alguma canalização presente, } \\
\text { normalmente próximo à construção } \\
\text { de pontes; evidência de modificações } \\
\text { antigas }\end{array}$ & $\begin{array}{c}\text { Margens modificadas; acima de } \\
80 \% \text { do rio modificado }\end{array}$ \\
\hline $\begin{array}{l}\text { 13. Características do } \\
\text { fluxo das águas }\end{array}$ & $\begin{array}{l}\text { Lâmina d'água acima de } 80 \% \\
\text { do canal do rio; ou menos de } \\
20 \% \text { do substrato exposto }\end{array}$ & $\begin{array}{l}\text { Lâmina d'água entre } 40 \text { e } 80 \% \text { do } \\
\text { canal do rio, elou maior parte do } \\
\text { substrato nos "rápidos" exposto }\end{array}$ & $\begin{array}{l}\text { Lâmina d'água escassa e } \\
\text { presente apenas nos remansos }\end{array}$ \\
\hline
\end{tabular}

Fonte: Adaptado de Hannaford et al. (1997), EPA (1987) e Rodrigues (2008).

Desta forma, a pontuação atribuída constituiu-se também enquanto uma ferramenta de análise planejamento e gestão ambiental local. 
O protocolo foi aplicado em 10 pontos espacialmente distribuídos na bacia, de modo a compreender os alto, médio e baixo cursos dos principais ribeirões da bacia, conforme coordenadas e altitudes dispostas no Quadro 3 (e espacializados na Figura 2). Além de levar em consideração o estágio de conservação das secções do curso, permitiu compreender o grau te interferência das classes de uso e ocupação do solo sobre o meio.

Quadro 3 - Localização e descrição dos pontos de coleta de informações para o PAR.

\begin{tabular}{|c|c|c|c|c|c|}
\hline Ponto & Latitude & Longitude & Altitude & Sub-Bacia & Descrição \\
\hline Ponto 1 & $17^{\circ} 41^{\prime} 21.78^{\prime \prime S}$ & $49^{\circ} 3 ' 52.05^{\prime \prime O}$ & 787 & Ribeirão da Areia & Alto curso; Córrego da Pipoca \\
\hline Ponto 2 & $17^{\circ} 43^{\prime} 30.72^{\prime \prime S}$ & $48^{\circ} 57^{\prime} 48.97^{\prime \prime O}$ & 736 & Ribeirão das Araras & Alto curso, Córrego da Samambaia \\
\hline Ponto 3 & $17^{\circ} 54^{\prime} 38.31 " \mathrm{~S}$ & $48^{\circ} 56^{\prime} 0.55^{\prime \prime O}$ & 642 & Ribeirão das Araras & Médio curso \\
\hline Ponto 4 & $17^{\circ} 53^{\prime} 51.53 " \mathrm{~S}$ & $49^{\circ} 1^{\prime} 6.71 " \mathrm{O}$ & 626 & Ribeirão da Areia & Médio curso \\
\hline Ponto 5 & $17^{\circ} 45^{\prime} 34.32^{\prime \prime S}$ & $49^{\circ} 5^{\prime} 9.88^{\prime \prime O}$ & 717 & Ribeirão da Areia & Trecho pós-urbano \\
\hline Ponto 6 & $17^{\circ} 50^{\prime} 44.09 " \mathrm{~S}$ & $49^{\circ} 10^{\prime} 25.55^{\prime \prime} \mathrm{O}$ & 860 & Ribeirão do Mimoso & Alto curso \\
\hline Ponto 7 & $17^{\circ} 57^{\prime} 19.20^{\prime \prime} \mathrm{S}$ & $49^{\circ} 5^{\prime} 9.76^{\prime \prime O}$ & 688 & Ribeirão do Mimoso & Médio curso \\
\hline Ponto 8 & $18^{\circ} 5^{\prime} 57.03 " \mathrm{~S}$ & $49^{\circ} 11^{\prime} 37.92^{\prime \prime O}$ & 668 & Ribeirão do Barreiro & Alto curso \\
\hline Ponto 9 & $18^{\circ} 5^{\prime} 41.77^{\prime \prime S}$ & $48^{\circ} 53^{\prime} 38.21 " \mathrm{O}$ & 535 & Ribeirão da Areia & Exutório da bacia \\
\hline Ponto 10 & $18^{\circ} 1^{\prime} 9.57^{\prime \prime S}$ & $48^{\circ} 55^{\prime} 44.64^{\prime \prime O}$ & 579 & Ribeirão da Areia & Baixo curso \\
\hline
\end{tabular}

Fonte: Os autores.

Figura 2 - Bacia Hidrográfica do Ribeirão da Areia: Pontos de coleta das informações.

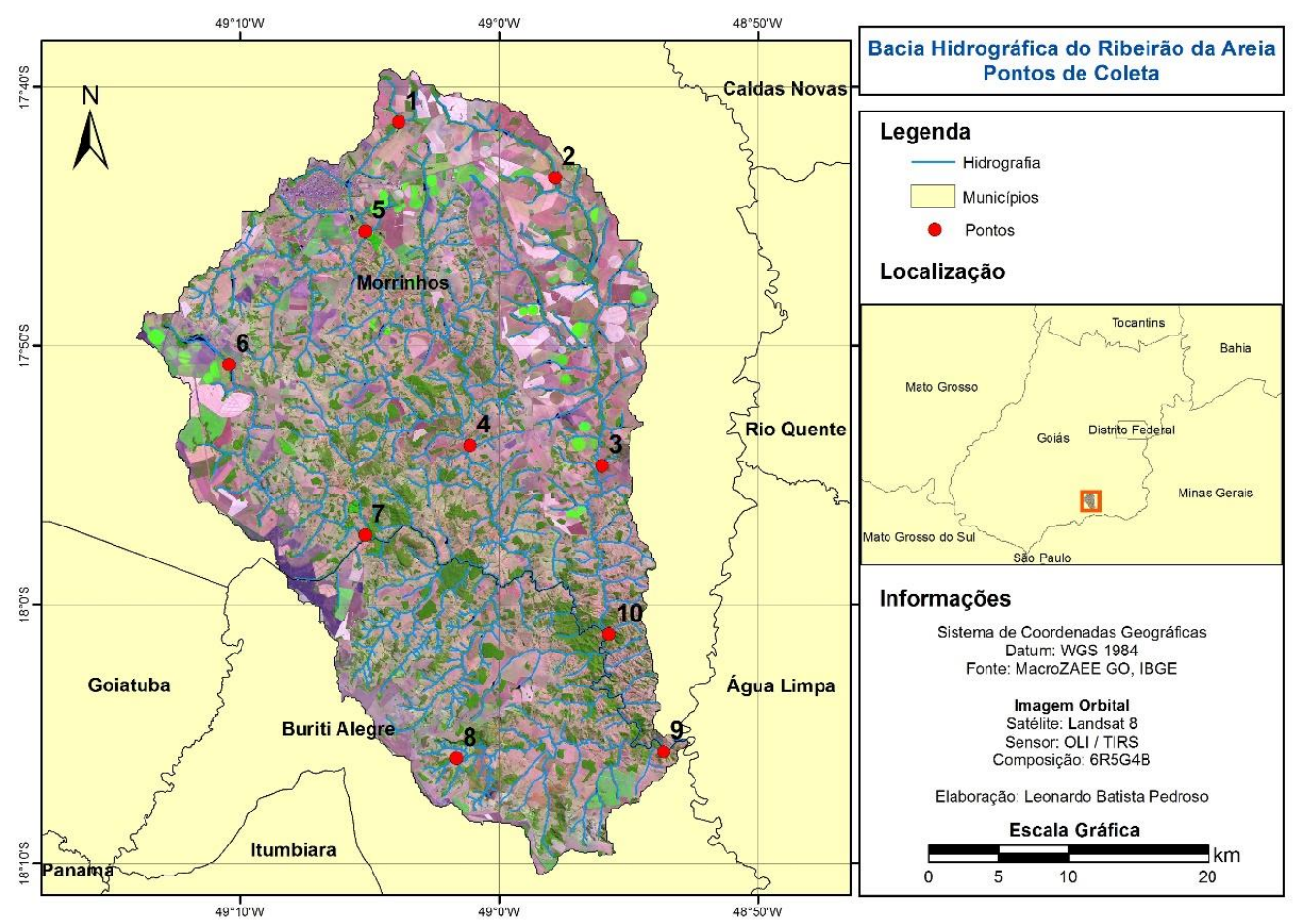

Fonte: Leonardo Batista Pedroso, 2017. 


\section{CARACTERIZAÇÃo DA ÁREA DE ESTUDO}

A Bacia Hidrográfica do Ribeirão da Areia está situada na Microrregião Geográfica Meia Ponte, localizada ao Sul do Estado de Goiás, contemplando uma área drenável de 1266,82 km² e perímetro de 190,61 km. A bacia insere-se predominantemente nos territórios municipais de Morrinhos e Buriti Alegre. Trata-se de uma microrregião composta por 21 municípios, cuja população total é de 387.992 habitantes, dos quais, a média geral para o sexo masculino é de $50,9 \%$ e para o sexo feminino de $49,1 \%$.

O Índice de Desenvolvimento Humano Municipal - IDHM regional varia entre 0,684 e 0,752, sendo o município de Itumbiara o que apresenta o maior índice. O menor índice é representado pelos municípios de Porteirão, Professor Jamil e Vicentinópolis. Morrinhos e Buriti Alegre, apresentam 0,734 e 0,710, respectivamente. O IDHM médio (regional) é de 0,709. O PIB - Produto Interno Bruto regional responde por mais de seis bilhões de reais anuais, com destaque para o município de Itumbiara que, sozinho, teve um PIB de $\mathrm{R} \$ 2.151 .447 .000$; cerca de 1/3 do total regional, que é de $\mathrm{R} \$$ 6.278.156.000 (IBGE, 2015).

A região apresenta cobertura vegetal natural com fitofisionomias típicas do Bioma Cerrado, o qual, encontra-se bastante alterado mediante a presença de áreas de pastagem e produção agrícola.

Conforme a classificação de Köppen-Geiger e com base nos dados do Instituto Nacional de Meteorologia (INMET), o clima de Morrinhos pode ser classificado como "Aw" - tropical quente e úmido, com chuvas mais concentradas no verão, tendo o inverno como um período de estiagem e temperaturas mais brandas, conforme se observa no Gráfico 1.

A precipitação pluviométrica anual para a região varia entre 1300 e $1600 \mathrm{~mm}$, tendo a média computada entre o período de 1973 e 2015 com 1489,5 mm. O período chuvoso corresponde ao intervalo entre os meses de outubro à março, estando todos com médias superiores a $100 \mathrm{~mm}$ mensais. Em contrapartida, os meses entre abril e setembro correspondem ao período de estiagem. Tem-se uma média de 116 dias com chuva por ano, sendo os meses de dezembro, janeiro e março com maior número, apresentando 20, 19 e 16 dias, respectivamente. A temperatura média oscila entre $19,9^{\circ} \mathrm{C}$ e $24,8^{\circ} \mathrm{C}$. Desta forma, podese inferir duas estações bem definidas: um verão quente e chuvoso, e um inverno seco e ameno. 
Gráfico 1 - Climograma de Morrinhos, GO.

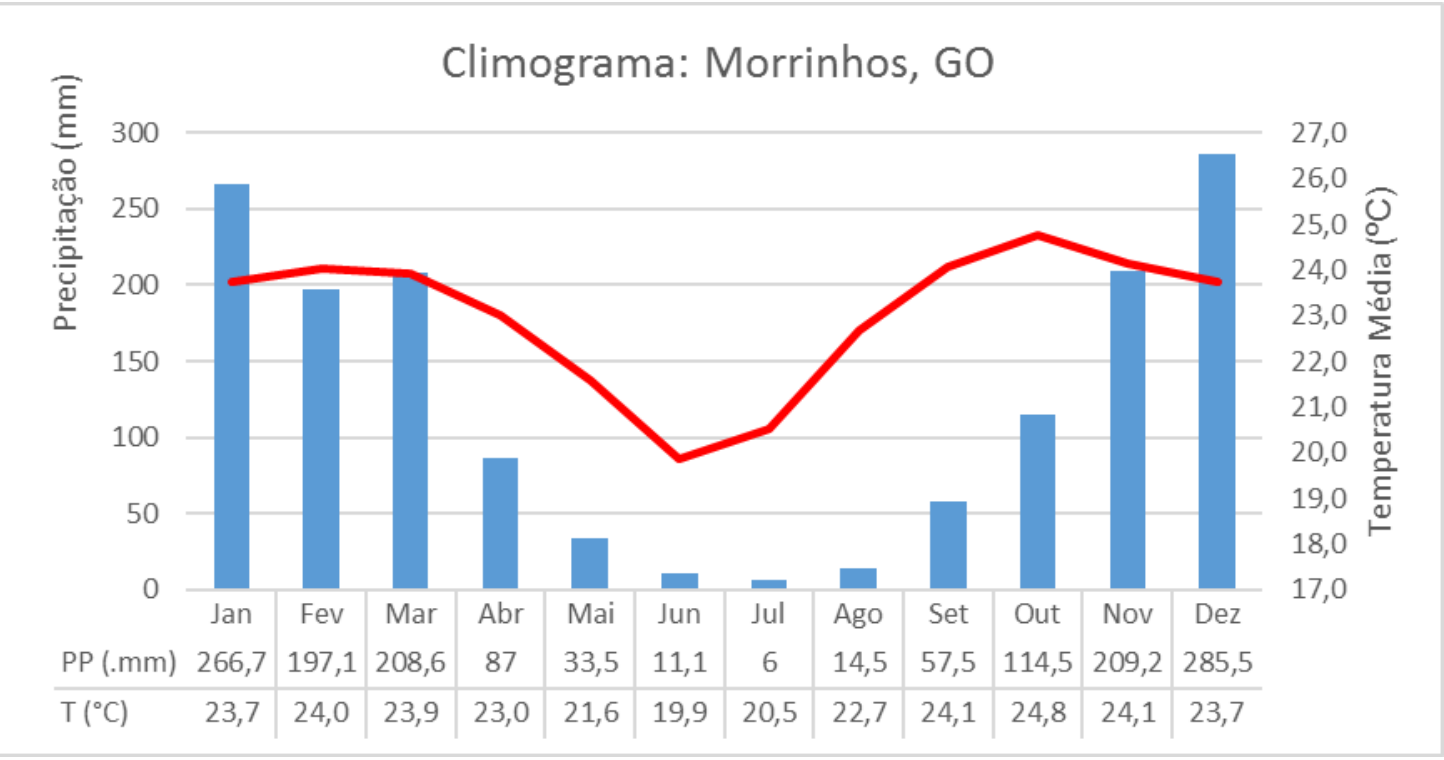

Fonte: Instituto Nacional de Meteorologia, 1973-2015.

A bacia hidrográfica do Ribeirão da Areia apresenta três classes de solos, sendo elas: cambissolo, latossolo e argissolo Os dois principais latossolos encontrados são o vermelhoescuro distrófico e o roxo distrófico, ambos associados à cobertura detrítico laterítica assentada sobre micaxistos do Grupo Araxá, ambos favoráveis ao desenvolvimento de espécies nativas do Cerrado na região (RADAMBRASIL, 1983; SANTOS, et al., 2013).

Na caracterização geomorfológica, o Ribeirão da Areia encontra-se na unidade do Planalto Rebaixado de Goiânia, cuja característica principal é presença de um vasto planalto dissecado, com variações altimétricas entre 650 e 850 metros de altitude. Coalesce com as unidades Depressões Intermontanas e com a parte mais baixa Planalto Setentrional da Bacia do Paraná (NASCIMENTO, 2001).

\section{PROTOCOLO DE AVALIAÇÃO RÁPIDA DE RIOS NA BACIA HIDROGRÁFICA DO RIBEIRÃO DA AREIA DURANTE O PERÍODO DE ESTIAGEM}

A aplicação do PAR ao longo dos pontos distribuídos na bacia resultou em resultados importantes que possibilitam a apreensão do quadro de qualidade ambiental das águas e de seus respectivos ambientes na bacia, indicando, em alguns casos, urgência no que tange o processo de desenvolvimento de ações de preservação. 
O estrato da distribuição da pontuação por parâmetros pode ser visualizado no conjunto de gráficos em sequência.

Gráfico 2 - Estrato individual do PAR para os pontos de análise.

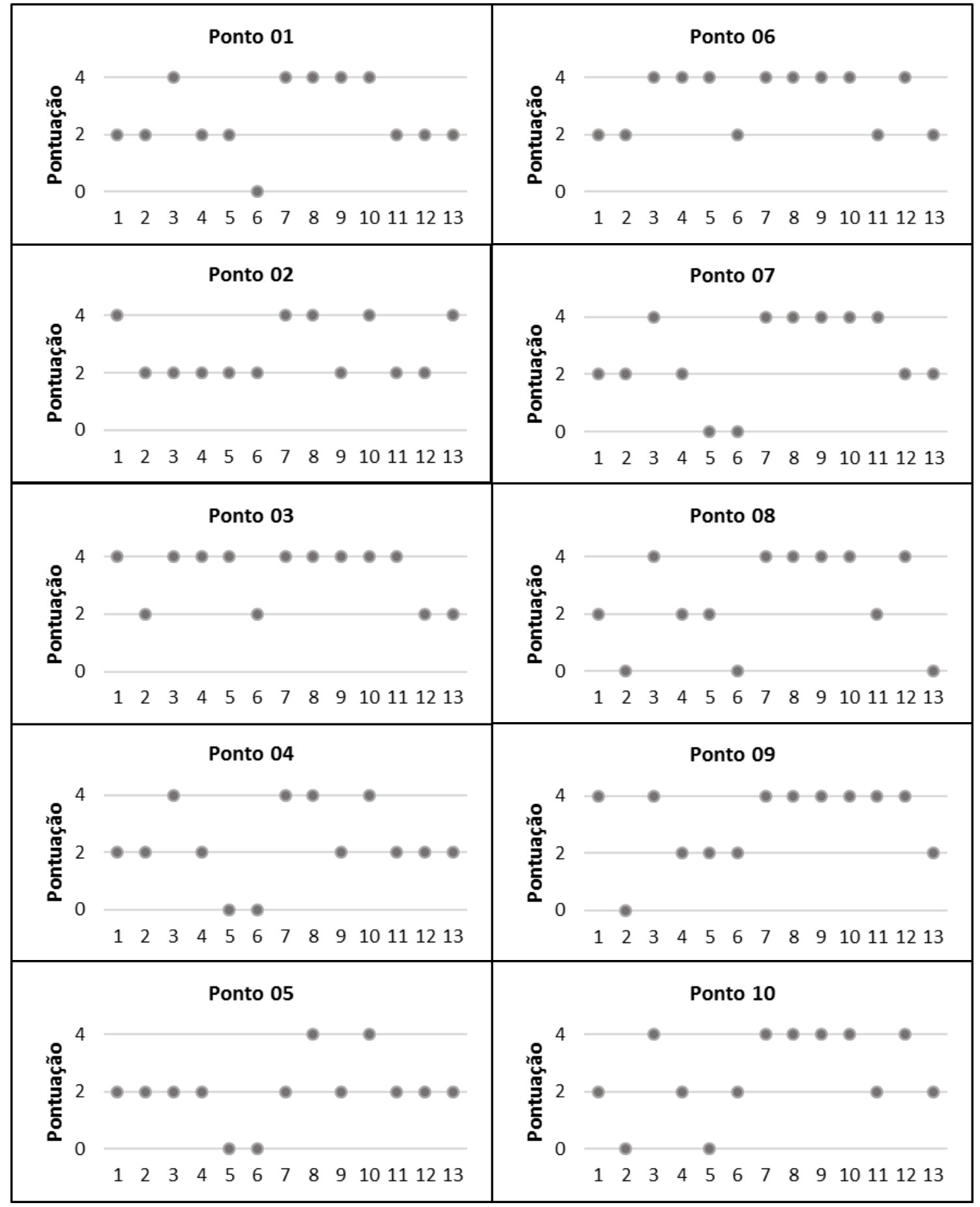

Fonte: Os autores, 2016. 
O primeiro ponto de análise, apresentado como "Ponto 1 - Córrego Pipoca", representa o alto curso do Ribeirão da Areia. O ponto está localizado em uma fazenda local, popularmente conhecida como "Fazenda dos Padres", onde são desenvolvidas atividades rurais, das quais destaca-se a pecuária.

$\mathrm{Na}$ respectiva área, o curso d'água analisado apresenta largura média de $3 \mathrm{~m}$, com profundidade média aproximada de $20 \mathrm{~cm}$. A avaliação da área ocorreu ao início da amanhã, com temperatura ambiente de $17^{\circ} \mathrm{C}$, e temperatura da água de $19^{\circ} \mathrm{C}$. Na aplicação do PAR, o respectivo local recebeu soma total de 34 pontos, enquadrando-se na categoria de condição ambiental considerada boa.

A análise do parâmetro 2, relativo à erosão próxima às margens do leito, indicou aspecto moderado, isto é, constatando-se determinada instabilidade nas margens, porém, não tão acentuada como se verifica em outros locais. A topografia local se mostrou bem plana, evitando assim, deslocamento de fluxos superficiais rápidos que contribuiriam para o desenvolvimento de processos erosivos acentuados. Da mesma forma, o fluxo d'água no leito não se enquadraria como trecho rápido. Por essa característica, o fundo do canal (Parâmetro 11), apresentou concentração de lama e areia.

Não se constataram alterações antrópicas significativas no leito, como disposição inadequada de resíduos ou poluição do canal. A cobertura vegetal ao longo do leito no trecho analisado caracteriza-se como parcial, com vegetação proveniente de bambuzal no local. Ao longo do canal, são encontradas espécies nativas ocupando as margens. Entretanto, a presença da mata ciliar não é densa, apresentando trechos como solo exposto e ocupando largura inferior à 12 metros, o que indica desflorestamento parcial da área.

Em relação aos demais parâmetros: não se constatou oleosidade na água; a água e os sedimentos não apresentaram odores específicos que poderiam indicar poluição por disposição de efluentes. Tais parâmetros mantiveram-se praticamente constantes ao longo dos demais pontos de análise.

A alteração do canal do rio pela existência de uma ponte no local foi intermediária, não modificando significativamente o fluxo local. A lâmina d'água no trecho estava próxima a 50\% do substrato do canal, devido ao período de estiagem e rebaixamento do nível da mesma.

O Ponto 2, por sua vez, é localmente conhecido como Córrego da Samambaia, e representa o alto curso do Ribeirão das Araras, sendo este um dos mais importantes cursos 
d'água da bacia hidrográfica do Ribeirão da Areia por conta de sua extensão. A análise foi realizada por volta das 08:30, com temperatura da água em $20^{\circ} \mathrm{C}$, e ambiente de $19^{\circ} \mathrm{C}$.

O trecho analisado não apresentou uso e ocupação do solo ativa, à exemplo de comparação com outros locais, como se verificou atividades agropecuárias. No entanto, o ponto situa-se bastante próximo à rodovia GO-213 (BR 490). Neste trecho, o córrego apresenta largura média de $3 \mathrm{~m}$ e profundidade de $50 \mathrm{~cm}$. Há uma área de represamento nas margens da rodovia, com a existência de canalização abaixo da mesma.

$\mathrm{Na}$ aplicação do PAR, este ponto também somou 36 pontos, enquadrando-se na categoria de condição "boa". A avaliação dos parâmetros indicou que o tipo de ocupação das margens, embora não preservadas, é de vegetação natural, com a presença de pequenas erosões e com estabilidade média dos solos. Constatou-se alterações de origem doméstica, com presença de lixo, a exemplo de garrafas plásticas e embalagens de produtos.

A cobertura vegetal do canal é parcial, situando-se às margens, não cobrindo o leito. A mata ciliar não é densa, apresentando trechos de solo exposto e, em alguns pontos, hidromorfizado, com presença de buritis (Mauritia flexuosa). A extensão da mata ciliar no trecho é média, na categoria entre 12 e 18m de largura, apresentando intervenção antrópica moderada.

Figura 3 - Ponto 02: Córrego da Samambaia: (A) área represada e presença de buritis durante período de estiagem; (B) leito parcial do córrego.
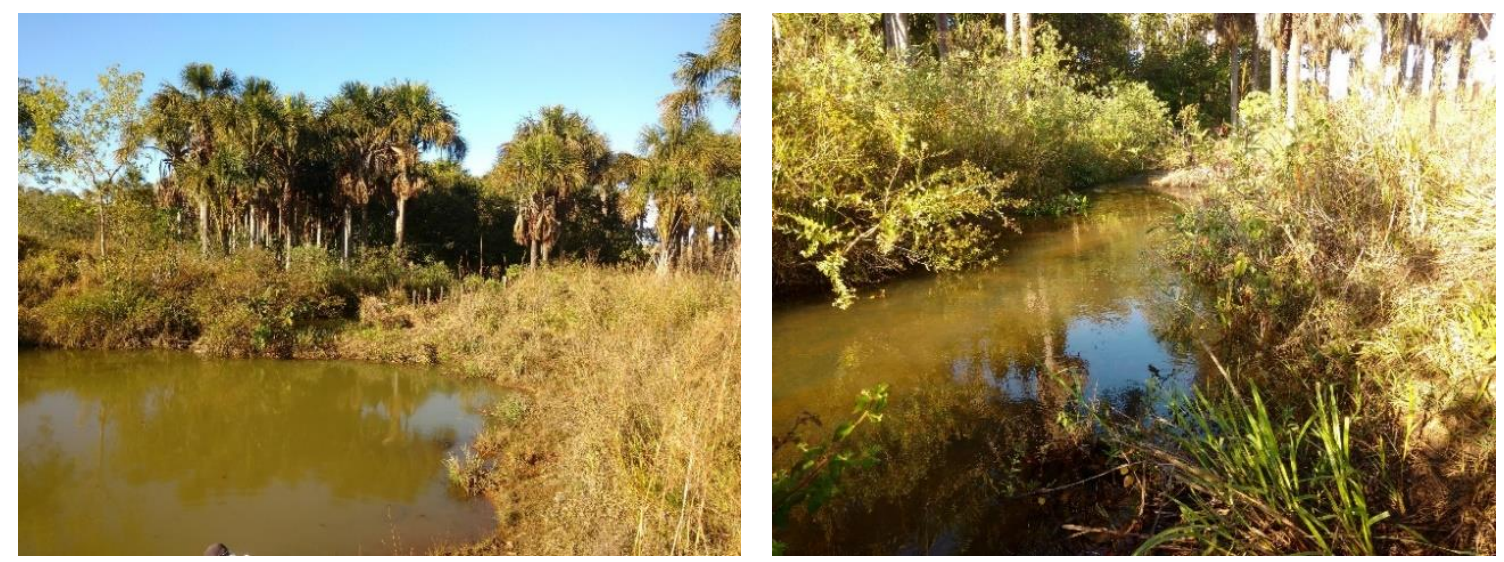

Fonte: Leonardo Batista Pedroso, 2016.

O Ponto 3 representa o médio curso do Ribeirão das Araras, estando à uma altitude de $642 \mathrm{~m}$, sendo este a sequência do curso d'água analisado no Ponto 2. Este local situa-se nas proximidades da rodovia GO 147, que liga os municípios de Morrinhos e Água Limpa, em 
propriedade privada, também próxima à ponte da respectiva rodovia. A largura média do canal no ponto foi aferida em $8 \mathrm{~m}$.

A soma da pontuação atribuída aos parâmetros de análise do PAR no respectivo ponto foi de 44 pontos, indicando "ótima" condição, recebendo pontuação máxima em todos itens, com exceção dos parâmetros 2 (que se refere à erosão próxima e/ou margens do corpo d'água), 6 (extensão da mata ciliar), 12 (alterações do canal) e 13 (características do fluxo das águas). A ocupação da área próxima ao trecho analisado se dá por pastagens degradadas, não se constatando a presença de gado. Porém, as margens do curso são ocupadas por vegetação natural. Há presença de alguns processos erosivos, indicando nível moderado para este parâmetro. No entanto, não houve alterações antrópicas significativas no leito e nas margens, ou seja, ausência de lançamento de esgotos e disposição inadequada de resíduos, bem como outras prováveis alterações.

O Ponto 4 representa o Ribeirão da Areia em seu médio curso, apresentando largura aproximada de $17 \mathrm{~m}$, com trechos mais estreitos e com fluxo rápido. A análise foi realizada por volta das 08:30, com temperatura da água em $20^{\circ} \mathrm{C}$. O trecho insere-se predominantemente em área rural, cuja característica é presença massiva de áreas de pastagem. Na avaliação do PAR, foram somados 30 pontos, categorizando o trecho na condição "boa".

Para os parâmetros relacionados à cobertura vegetal, a análise indicou cobertura vegetal parcial sobre o leito, bem como a frágil presença de mata ciliar, com grande desflorestamento, não ultrapassando $12 \mathrm{~m}$ de extensão.

O Ponto 5 situa-se em um trecho pós-urbano, isto é, nas proximidades das áreas limítrofes da malha urbana da cidade de Morrinhos, cujo uso e ocupação do solo local se dá por pastagens e cultivos agrícolas em propriedades rurais locais. O referido trecho situa-se ao lado de uma ponte, também nas proximidades da Estação de Tratamento de Esgoto - ETE da cidade de Morrinhos, contemplando-se enquanto um ponto estratégico de análise. Além de vicinal local, o entorno do trecho analisado possui fomo forma de uso e ocupação do solo áreas de pastagem degradadas e arbustos resquícios da vegetação de Cerrado.

Há erosões nas margens, mais visíveis pelo rebaixamento do nível da água durante período de estiagem. Tratam-se de processos moderados, porém, frequentes. Verifica-se também no entorno do ponto, a presença de resíduos plásticos provenientes de uso doméstico, conforme Parâmetro 3 do PAR, cuja aplicação, como se verifica no gráfico a seguir, resultou na soma de 26 pontos, enquadrando-se na categoria "regular". 
A água apresentou leve odor, associado à decomposição de matéria orgânica. Não foi constatada oleosidade na água; entretanto, em relação à cor, apresentou tonalidade verdeescura e alta turbidez. O tipo de fundo de leito verificado foi o coberto por lama e areia; e os sedimentos, ao contrário da água, não apresentaram cheiro característico.

O Ponto 06 representa o alto curso do Ribeirão do Mimoso, com largura média do canal no trecho de $1,5 \mathrm{~m}$. A soma da pontuação atribuída aos parâmetros do PAR foi de 42 pontos, categorizando sua condição como "ótima”.

As margens do curso são ocupadas por vegetação ripária de largura inferior a 12 metros, porém, intensa e diversa, com presença de árvores e arbustos com distintos portes. A cobertura vegetal sobre o leito do córrego também é bastante significativa, atribuindo "Total" ao Parâmetro 4. O solo no local é bastante hidromorfizado, apresentando erosões moderadas próximas ao leito, dificultando acesso ao mesmo. As áreas da planície no entorno do trecho são ocupadas por pequenas áreas de pastagem em considerável estágio de degradação (conforme se verifica na figura a seguir) e, ao longo do segmento do canal, constatam-se também culturas de cana-de-açúcar e tomateiro irrigado por sistema de pivô-central, o que eleva consideravelmente o consumo dos recursos hídricos a nível local, sobretudo no período de estiagem.

O Ribeirão do Mimoso, em seu médio curso, é representado pelo Ponto 07, situandose entre as coordenadas de 1757'19.20" de latitude Sul e 495'9.76" de longitude Oeste, com altitude de $688 \mathrm{~m}$; isto é, 172 metros mais baixo que o seu trecho de análise no alto curso, analisado no item anterior. Neste ponto, o Ribeirão apresenta largura média de $7 \mathrm{~m} \mathrm{e}$ profundidade entre 30 e $40 \mathrm{~cm}$, correndo sobre leito de seixos e cascalhos.

A soma da pontuação atribuída ao PAR foi de 34 pontos, condição considerada "boa". $\mathrm{O}$ trecho recebeu menor avaliação nos parâmetros 5 e 6 , que dizem respeito à presença e extensão da mata ciliar, respectivamente. A ocupação da área por áreas de pastagem é extensa, com grande nível de desmatamento no local, também influenciadas pelas erosões consideradas de nível e intensidade moderada. Desta forma, além da baixa diversidade fitofisionômica, os poucos indivíduos vegetais situam-se bem próximos às margens, cobrindo parcialmente o leito no trecho analisado. A lâmina d'água estava bem abaixo do substrato exposto, indicando nível entre 40 e $80 \%$ do canal, a qual apresentou transparência e baixa turbidez em pontos de maior profundidade.

O Ponto 08 representa Ribeirão do Barreiro, que insere-se no município de Buriti Alegre, desaguando no Ribeirão da Areia, a poucos quilômetros do exutório da bacia, em seu 
encontro com o Rio Piracanjuba. A aplicação do PAR para este trecho do Ribeirão do Barreiro resultou na soma de 32 pontos, enquadrando-se na categoria "boa".

Neste trecho, o Ribeirão do Barreiro apresenta largura média de 1,5 m, com profundidade aferida entre 15 e $20 \mathrm{~cm}$. O tipo de ocupação das margens enquadra-se na segunda categoria, representado por campo de pastagem. As margens se apresentaram bastante instáveis, com acentuado processo erosivo e presença significativa de material inconsolidado. Verificou-se inúmeras áreas descobertas e susceptíveis à ocorrência de processos semelhantes, o que poderá ocasionar maior degradação da área, afetando a disposição do canal. Tal aspecto pode ser verificado na figura a seguir:

Figura 4 - Ribeirão do Barreiro - Alto curso: (A) leito e altura da lâmina d'água; (B) processos erosivos nas margens.
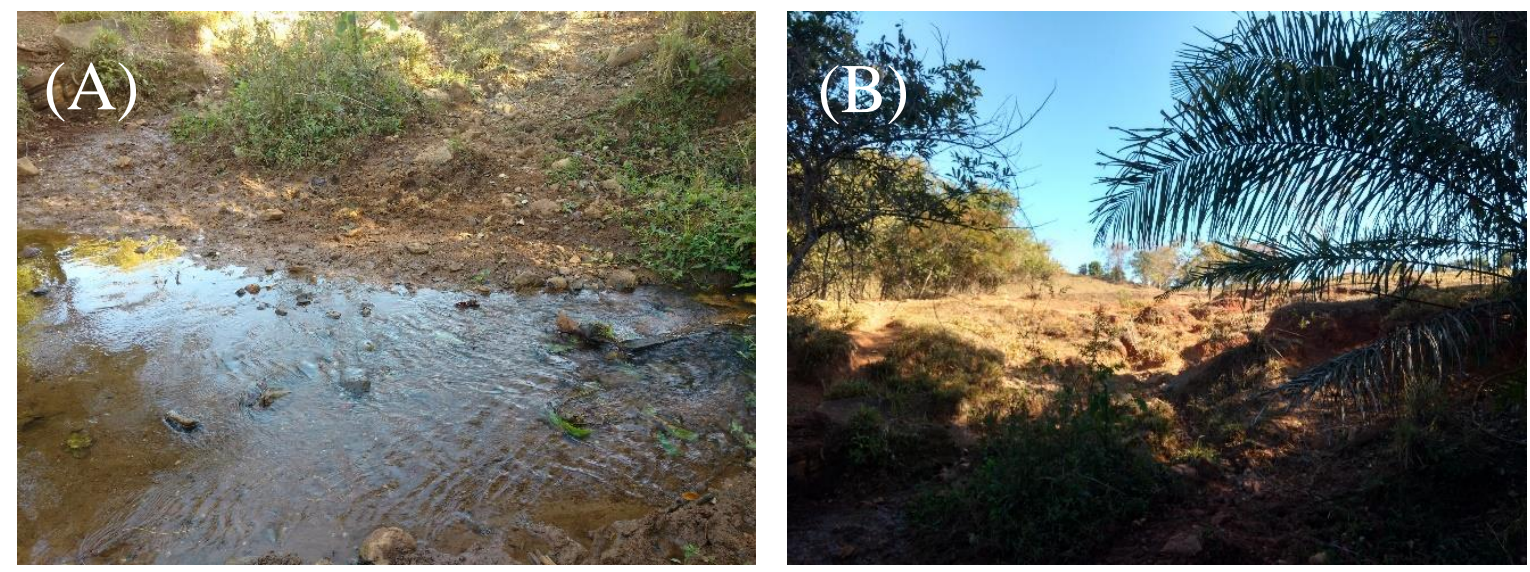

Fonte: Leonardo Batista Pedroso, 2016.

Como se verifica na figura, a lâmina d'água se apresentou bastante escassa, com grande parte do substrato do canal exposto, recebendo avaliação baixa neste parâmetro (13).

O Ponto 09 se localiza nas coordenadas de $18^{\circ} 5^{\prime} 41.77^{\prime \prime}$ de latitude Sul e 48 $533^{\prime} 38.21 "$ de longitude Oeste, nas proximidades do desague do Ribeirão da Areia no Rio Piracanjuba. Embora o propósito de se avaliar este ponto seja o de compreender a qualidade das águas deste ribeirão em termos de contribuição para o Rio Piracanjuba (tributário do Rio Paranaíba), há de se compreender a importância de processos naturais como a capacidade de autodepuração dos cursos d'água ao longo de seu percurso, sobretudo em trechos rápidos e turbulentos.

O Ribeirão da Areia neste ponto apresentou largura média de $23 \mathrm{~m}$, ressaltando que tal aferição se deu em período de estiagem. A profundidade estimada neste ponto foi de $2,5 \mathrm{~m}$
Pedroso e Colesanti, 2018. 
$\mathrm{Na}$ avaliação do protocolo, foi atribuído a este ponto um total de 40 pontos, categorizando-o como "bom".

A análise do PAR apontou ausência de alterações antrópicas nas margens (conforme Parâmetro 3). A cobertura vegetal verificada sobre o leito é parcial, permitindo sombreamento das encostas, barrancos e conglomerados no leito. A densidade da mata ciliar, no entanto, enquadrou-se entre 50 e $80 \%$, com largura variando entre 12 e $18 \mathrm{~m}$, apresentando pequena influência antrópica. Não foram encontrados resíduos nas margens, tampouco a presença de oleosidade nas margens e na água.

O Ponto 10, por fim, permite a compreensão do estado do baixo curso do Ribeirão da Areia e também dos Ribeirões do Mimoso e das Araras, uma vez que são entendidos como seus tributários. Na aplicação do PAR, o trecho recebeu 34 pontos, enquadrando-se na categoria "boa".

O tipo de ocupação da área deste ponto do Ribeirão da Areia se dá por vegetação natural, sendo o acesso por meio de propriedade rural, onde se desenvolve criação de bovinos. Há, desta forma, muitas áreas de pastagem próximas ao local de análise. Verificou-se próximo às margens intensa atividade erosiva, tornando as encostas instáveis. Tal condição associada à baixa densidade da vegetação ciliar contribui para a susceptibilidade de intensificação destes processos. A mata ripária dispôs de largura entre 12 e 18 m, com trechos de solo exposto, indicando desflorestamento.

A área inundável do canal e o fundo do mesmo apresentam muitas rochas, não se verificando alterações provenientes de ações antrópicas no leito, que poderiam interferir no padrão normal. Tais rochas são cobertas no período chuvoso, enquanto que a análise no período de estiagem demonstrou que a lâmina d'água ocupou entre 40 e $80 \%$ do canal, com grande parte do substrato exposto. Próximo ao local, há também trecho lento, com presença de remanso da água.

O resumo do estrato da aplicação dos protocolos é apresentado no Gráfico 3.

É possível constatar pela análise do gráfico, que dos dez pontos, sete encontram-se na condição boa, dois na condição ótima e somente um regular. As maiores pontuações dos extratos do PAR foram de 44 e 42 pontos, respectivamente, enquanto as menores foram de 26 e 30, respectivamente. O mapa em sequência sintetiza a espacialização dos resultados da aplicação do protocolo. 
Gráfico 3 - Estrato do PAR.

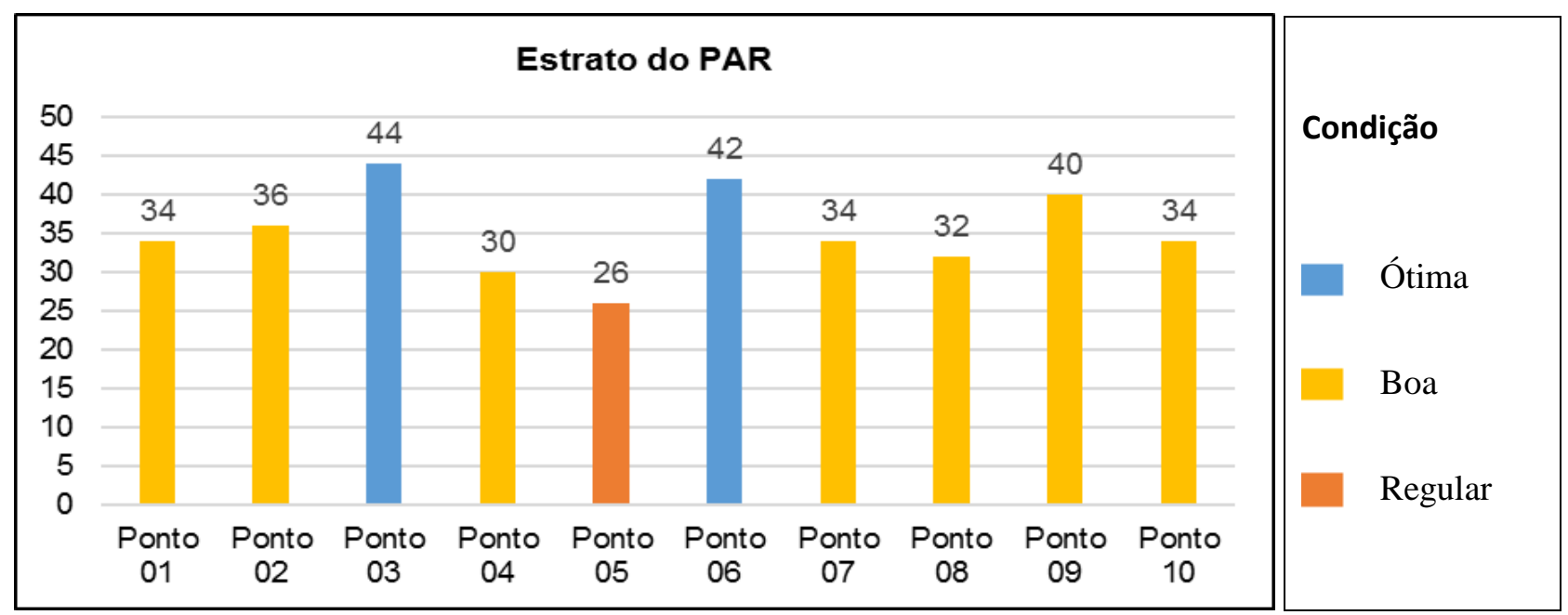

Fonte: Os autores, 2016.

Figura 5 - Bacia Hidrográfica do Ribeirão da Areia: Espacialização dos resultados do PAR.

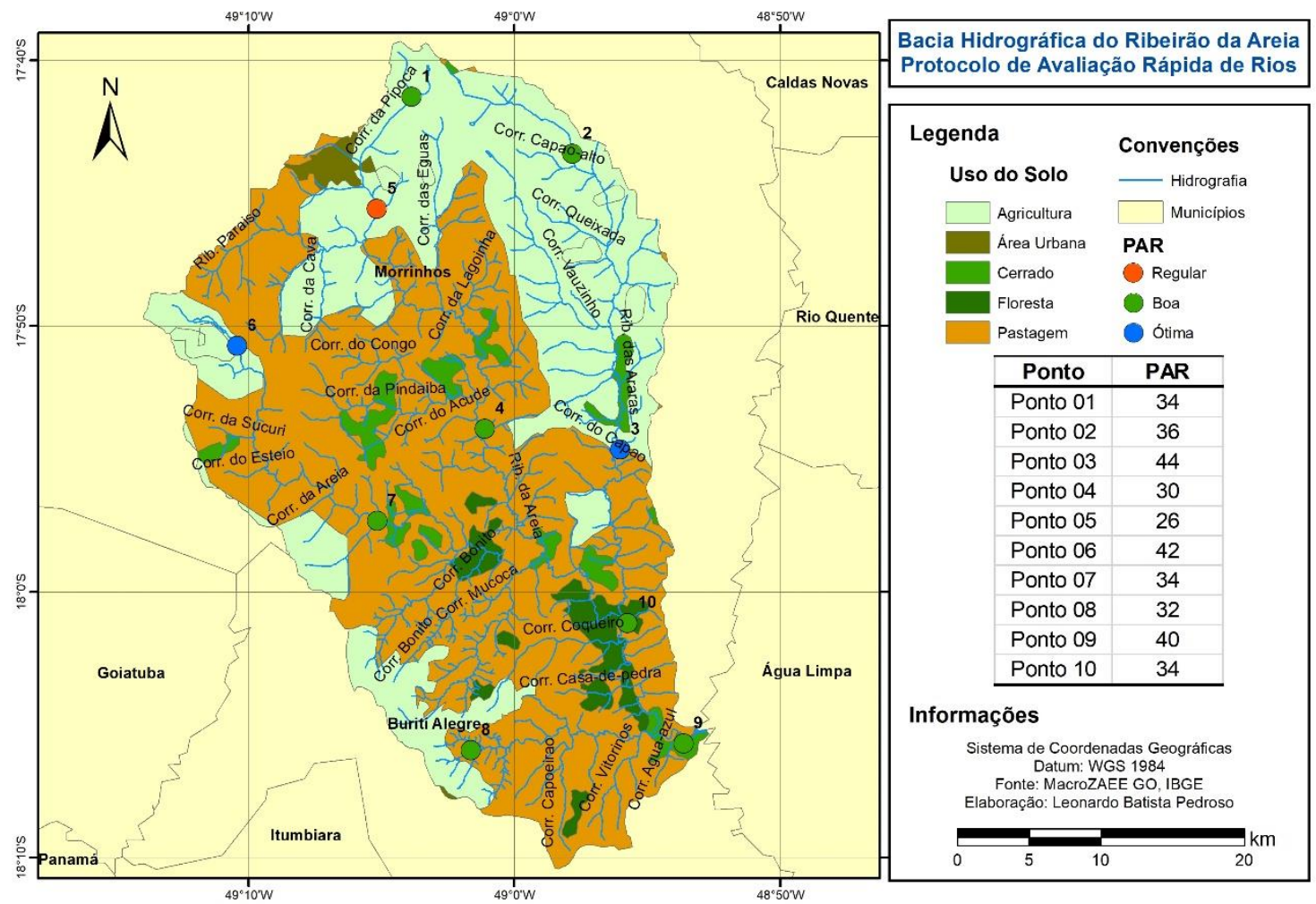

Fonte: Leonardo Batista Pedroso, 2018.

Não se verifica um padrão específico quanto à espacialização dos resultados, pois, em geral, nove dos dez pontos apresentaram boa ou ótima condição de suas águas e respectivos entornos. 


\section{CONSIDERAÇÕES FINAIS}

A aplicação de métodos que visam a avaliação qualitativa dos corpos hídricos é de grande importância para a gestão de bacias hidrográficas, uma vez que possibilita o diagnóstico ambiental sobre as águas e seus respectivos entornos.

No caso dos pontos distribuídos na Bacia Hidrográfica do Ribeirão da Areia, verificou-se ocupação das margens dos corpos hídricos por atividades agropecuárias, ligadas à pastagem para gado e diferentes culturas agrícolas. Assim sendo, em praticamente todos os trechos, a cobertura vegetal nativa encontra-se de alguma forma onerada, apresentando largura inferior ao exigido pela legislação vigente e com menor densidade, indicando alterações provenientes de atividades antrópicas.

Por outro lado, não há a presença de processos erosivos extremos que afetem o curso natural dos leitos, da mesma forma em que não se constatam alterações quanto ao aspecto organoléptico de análise das águas, sobretudo em termos de cheiro

Em âmbito geral, a bacia dispõe de boa condição do ambiente entorno das águas. A média geral da bacia respondeu pelo total de 36 pontos do PAR. No entanto, vale a observância de particularidades dos trechos analisados. Assim sendo, a replicação da metodologia para averiguação da qualidade da água deve ser adaptada à realidade da bacia, de modo a contemplar trechos e/ou pontos que respondam pela real abordagem espacial e qualitativa da bacia.

Importante frisar que as conclusões obtidas por meio das análises referem-se a características dos pontos estudados. Ainda que represente grande parte da realidade da bacia, não é possível afirmar com exatidão que todos os trechos do recorte espacial sejam dotados da mesma característica. Para pesquisas de cunho governamental, com maior disponibilidade de recursos e mão-de-obra, recomenda-se o emprego de mais pontos de análise, de modo que um mesmo curso d'água não apresente grandes extensões sem monitoramento. $\mathrm{O}$ desenvolvimento de planilhas e softwares que viabilizem a organização destes dados é um aspecto a ser observado com maior atenção.

É necessário que tais pesquisas sejam realizadas periodicamente, como forma de monitoramento das águas, juntamente com planos de ação de órgãos competentes, evitando quadros severos de qualidade e disponibilidade, como a escassez hídrica constatada na área de estudo durante segundo período de amostragem. Assim, é possível avaliar e identificar fragilidades ambientais, possibilitando maior eficácia na atuação do poder público face aos problemas recorrentes. 


\section{REFERÊNCIAS}

BARBOUR M. T.; GERRISTSEN J.; SNYDER B. D.; STRIBLING J. B. Rapid Bioassessment Protocols for Use in Streams and Wadeable Rivers: Periphyton, Benthic Macroinvertebrates and Fish. 2. ed. Washington: EPA, 1999. 339 p.

BIZZO, M. R. O.; MENEZES, J.; ANDRADE, S. F. Protocolos de Avaliação Rápida de Rios (PAR). Caderno de Estudos Geoambientais, Campos dos Goytacazes, v.4, n.1, p.05-13, 2014.

BRASIL. Conselho Nacional do Meio Ambiente. Resolução n 357, de 17 de março de 2005. BRASIL. Ministério do Meio Ambiente. Plano Nacional de Recursos Hídricos. Programas nacionais e metas. 4.ed. Brasília, 2003. 84 p.

CALliStO, M.; FERREIRA, W. R.; MORENO, P.; GOULART, M. \& PETRUCIO, M. Aplicação de um protocolo de avaliação rápida da diversidade de habitats em atividades de ensino e pesquisa (MG-RJ). Acta Limnologica de Brasil, Rio Claro, v.14, n.1, 2002. p. 9198.

COLLISCHONN, W; TASSI, R. Introduzindo Hidrologia. Porto Alegre: IPH UFGRS, 2010.

GOIÁS. Sistema Estadual de Estatística e de Informações Geográficas de Goiás. Disponível em: <http://www.sieg.go.gov.br/>. Acesso em: 03 dez. 2015.

HANNAFORD, M. J.; BARBOUR, M. T.; RESH, V. H. Training reduces observer variability in visual-based assessments of stream habitat. Journal North American Benthological Society, Washington, v.4, n.16, p. 853-860, 1997.

INSTITUTO BRASILEIRO DE GEOGRAFIA E ESTATÍSTICA - IBGE (Brasil). Dados censitários de Municípios de Goiás. Disponível em: <http://www.cidades.ibge.gov.br>. Acesso em: 27 mai. 2015.

OBSERVATÓRIO DO MUNDO DO TRABALHO. Estudos Microrregionais: Estudos e pesquisas econômicas, sociais e educacionais sobre as microrregiões do Estado de Goiás Microrregião do Meia Ponte. Goiânia: IFG, 2013. 51 p.

PHILIPPI JR., A.; MARTINS, G. Águas de abastecimento. In: PHILIPPI JR., A. (Org.). Saneamento, saúde e ambiente: fundamentos para um desenvolvimento sustentável. Barueri: Manole, 2005. p. 117-180. 
RODRIGUES, A. S. L. Adequação de um protocolo de avaliação rápida para o monitoramento e avaliação ambiental de cursos d'água inseridos em campos rupestres. 2008. 188 f. Dissertação (Mestrado em Ciências Naturais) - Programa de Pós-Graduação em Evolução Crustal e Recursos Naturais, Departamento de Geologia, Escola de Minas, Universidade Federal de Ouro Preto, Ouro Preto, 2008.

SANTOS, H. C. Sistema Brasileiro de Classificação de Solos. 3. ed. Brasília: EMBRAPA, 2013. $353 \mathrm{p}$.

VON SPERLING, M. Introdução à qualidade das águas e ao tratamento de esgotos. 1.ed. Belo Horizonte: Departamento de Engenharia Sanitária e Ambiental da UFMG, 1996. 452 p. 